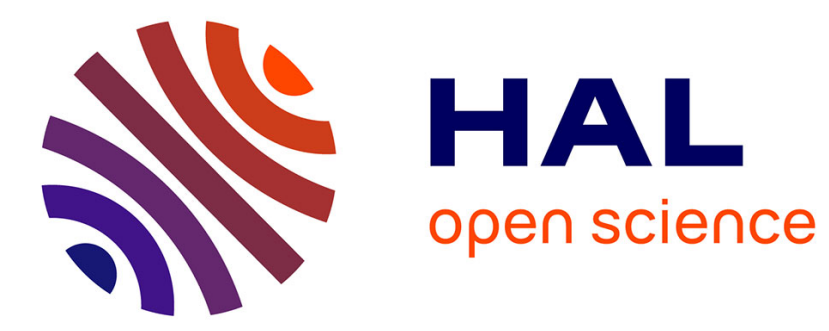

\title{
The lower is not always the better: a more comprehensive understanding of loop diuretics in heart failure
}

\author{
Nicolas Girerd, G. Michael Michael Felker
}

\section{- To cite this version:}

Nicolas Girerd, G. Michael Michael Felker. The lower is not always the better: a more comprehensive understanding of loop diuretics in heart failure. European Journal of Heart Failure, 2021, 23 (7), pp.1120-1121. 10.1002/ejhf.2182 . hal-03413998

\section{HAL Id: hal-03413998 \\ https://hal.univ-lorraine.fr/hal-03413998}

Submitted on 4 Nov 2021

HAL is a multi-disciplinary open access archive for the deposit and dissemination of scientific research documents, whether they are published or not. The documents may come from teaching and research institutions in France or abroad, or from public or private research centers.
L'archive ouverte pluridisciplinaire HAL, est destinée au dépôt et à la diffusion de documents scientifiques de niveau recherche, publiés ou non, émanant des établissements d'enseignement et de recherche français ou étrangers, des laboratoires publics ou privés. 


\title{
The lower is not always the better: a more comprehensive understanding of loop diuretics in heart failure
}

\author{
Nicolas Girerd $^{1}$, G. Michael Felker ${ }^{2}$ \\ ${ }^{1}$ Université de Lorraine, Centre d'Investigations Cliniques Plurithématique 1433, Institut Lorrain du \\ Cœur et des Vaisseaux Louis Mathieu, CHRU de Nancy, INSERM DCAC, F-CRIN INI-CRCT, \\ Nancy, France. \\ ${ }^{2}$ Duke Clinical Research Institute, Durham, North Carolina, USA.
}

Key words: Heart failure, Cardiac edema, Diuretics, Cardiovascular diseases.

The development of congestion is one of main causes leading to urgent hospitalization and subsequent cardiovascular mortality in patients with heart failure (HF). ${ }^{1}$ Sodium and water retention affects a variety of organs, including the heart itself, the lungs, and the kidneys. ${ }^{2}$ Loop diuretics have been the cornerstone of congestion management in HF for more than 50 years. ${ }^{3}$ Although they have never been shown to decrease mortality in randomized trials, decades of routine clinical use has shown that IV administration of loop diuretics results in rapid diuresis and decongestion in the majority of patients admitted for worsening HF. However, a significant level of concern have been expressed in the past years with regards to diuretic use, mainly because they activate the renin-angiotensinaldosterone system and sympathetic nervous system, both of which are detrimental in heart failure. ${ }^{4}$

In light of these concerns, current guidelines stipulate that "the lower the better". Specifically, the guidelines advocate (in the Web addenda) for the "use [of the] minimum dose necessary to maintain euvolaemia - the patient's 'dry weight' (i.e. to keep the patient free of symptoms and signs of congestion)". ${ }^{3}$ Recently, this approach has been taken one step further with the publication of trial halting loop diuretics in chronic HF patients with low dose of loop diuretics: The multicenter ReBIC (Rede Brasileira de Estudos em Insuficiencia Cardiaca) trial randomized 188 stable HF outpatients without evidence of clinical congestion to furosemide withdrawal or maintenance. ${ }^{5}$ No significant difference in patients' assessment of dyspnoea was observed between the 2 groups. In addition, at 90 days, furosemide was reinitiated in only 1 in 4 patients in the furosemide withdrawal group. ${ }^{5}$ Given these data, should we consider efforts to systematically discontinue diuretics in stable heart failure patients?

In this month's journal, Dr Dauw and colleagues report evidence on the natriuretic and urine output changes following diuretic omission in 40 ambulatory HF without clinical evidence of congestion treated with 1-2 mg bumetanide ${ }^{6}$. Urine collections were performed on 2 consecutive days; On the first day, patients took their usual loop diuretic dose and on the second day, loop diuretics were withheld. In addition the authors recruited $26 \mathrm{HF}$ patients who were not treated with chronic diuretic therapy as a control group. The paper answers two very sound and relevant clinical questions.

First, "is the sodium and water equilibrium in HF patients treated with loop diuretics similar to a subject with HF who do not require chronic diuretics?". This paper is confirming clinical intuition as it shows that the diuresis and natriuresis of stable HF patients treated with low dose loop diuretics is actually similar to the one observed in control subjects (approximately $1.5 \mathrm{l} / \mathrm{day}$ and approximately 10 $\mathrm{mmol} / 24 \mathrm{~h}$ of sodium/day). Loop diuretics do appear to enable HF patients to sufficiently correct sodium/water retention related to HF to reach a "normal" equilibrium. Importantly, most of the natriuresis occurred within 6 hours of diuretic intake.

The second question answered by this study is "What happens to the sodium and water equilibrium when we discontinue loop diuretics?". Very interestingly, this study shows that 24 to 48 hours after diuretics omission, natriuresis decrease by $50 \%$ and urine output decrease by approximately $30 \%$. The relative equilibrium observed under loop diuretic treatment is consequently swiftly broken when diuretics are withheld. 
Many points should be highlighted following the publication of this highly insightful paper.

First, this paper suggests that low/moderate dose of diuretics "normalize" the sodium/water retention inherent to congestive HF as the levels of diuresis/natriuresis under low dose loop diuretics is similar to the diuresis/natriuresis observed in patients not needing diuretics.

Second, Loop diuretic induce a short-term natriuresis (most of the natriuresis was observed within 6 hours of diuretics intake). This reinforce old data, usually gathered in healthy individuals. What has been highlighted over the years is true, and this gives credence to splitting loop diuretics dose during the day to minimize periods of post diuresis sodium avidity.

Apparently, the clinical gestalt of HF physicians leading to diuretic dose optimization/downtitration is rather accurate, at least in the setting of this study, as patients that were clinically considered as needing diuretics had important natriuresis drop following loop diuretics withhold.

Following those important results, how should we manage loop diuretics in HF patients without clinical congestion and low dose of loop diuretics? Should we systematically try to witheld loop diuretics, as in the ReBIC trial, or show we consider that HF patients need diuretics to restore their sodium/water equilibrium? The question will be definitively answered in a large trial, but, in the meanwhile, we may propose a pragmatic approach to this problem.

Patients without clinical signs of congestion may have biological or echocardiographic signs of congestion, and those signs are associated with HF hospitalizations. ${ }^{1,2}$ Before withholding loop diuretics, verifying that patients do not have pulmonary congestion evidenced by lung ultrasound or a dilated inferior vena cava suggesting raised systemic venous pressure could provide additional assurance of clinical stability.

As important changes in sodium/water homeostasis are to be expected in the next days, a close follow-up should be envisaged following diuretics discontinuation, possibly within 5 days. This follow-up could be performed by trained/dedicated HF nurses.

The inability to stop diuretics should not be perceived as a failure. Some patients do need diuretics and as Voltaire would say, "le mieux est l'ennemi du bien" (literally, the best is the enemy of the good, Dictionnaire philosophique,1770). Although diuretic discontinuation may be feasible in carefully selected patients, chronic loop diuretics are central to maintaining sodium and fluid balance in many patients with chronic HF.

\section{Bibliography}

1. Girerd N, Seronde MF, Coiro S, et al. Integrative Assessment of Congestion in Heart Failure Throughout the Patient Journey. JACC Heart failure 2018; 6(4): 273-85.

2. Pellicori P, Platz E, Dauw J, et al. Ultrasound imaging of congestion in heart failure: examinations beyond the heart. Eur J Heart Fail 2020.

3. Ponikowski P, Voors AA, Anker SD, et al. 2016 ESC Guidelines for the diagnosis and treatment of acute and chronic heart failure: The Task Force for the diagnosis and treatment of acute and chronic heart failure of the European Society of Cardiology (ESC). Developed with the special contribution of the Heart Failure Association (HFA) of the ESC. Eur J Heart Fail 2016; 18(8): 891-975.

4. Felker GM, O'Connor CM, Braunwald E, Heart Failure Clinical Research Network I. Loop diuretics in acute decompensated heart failure: necessary? Evil? A necessary evil? Circ Heart Fail 2009; 2(1): 56-62.

5. Rohde LE, Rover MM, Figueiredo Neto JA, et al. Short-term diuretic withdrawal in stable outpatients with mild heart failure and no fluid retention receiving optimal therapy: a double-blind, multicentre, randomized trial. Eur Heart J 2019; 40(44): 360512.

6. Dauw J, Martens P, Tersalvi G, et al. Diuretic response and effects of diuretic omission in ambulatory heart failure patients on chronic low-dose loop diuretic therapy. Eur J Heart Fail 2021; 23(7): 1110-9. 